\title{
Multi-DOF (Degree of Freedom) Articulating Laparoscopic Instrument is an Effective Device in Performing Challenging Sutures
}

\author{
Sa-Hong Min, M.D. ${ }^{1}$, Yo-Seok Cho, M.D. ', Kibum Park, M.D., Ph.D. ${ }^{1}$, Yoontaek Lee, M.D. ${ }^{1}$, Young Suk Park, M.D. ', \\ Sang-Hoon Ahn, M.D. ${ }^{1,2}$, Do Joong Park, M.D., Ph.D. ${ }^{1,2}$, Hyung-Ho Kim, M.D., Ph.D. ${ }^{1,2}$ \\ 'Department of Surgery, Seoul National University Bundang Hospital, Seongnam, ${ }^{2}$ Department of Surgery, Seoul National University College of Medicine, \\ Seoul, Korea
}

Purpose: Although laparoscopic surgery had been performed in clinical practice for over 30 years, there has not been much improvement on instruments. Several articulating laparoscopic instruments have been developed including the robotic system. A new multi-degree of freedom (DOF) articulating laparoscopic device has been developed. We compared the ability to perform challenging sutures between the new device and the robotic system.

Methods: Five experienced surgeons with over 100 laparoscopic surgery cases performed the suture task with both instruments. Everyone was new at articulating instruments including a robotic system. The suturing task consisted of two vertical sutures, downward and upward vertical direction. The duration of needle grabbing, first surgical tie, square tie, and the final reverse tie was measured.

Results: When doing the downward suture, the median time to complete the suture was 127 vs. 136 seconds for ArtiSential ${ }^{\mathbb{B}}$ and the robot, respectively $(p=0.754)$. Other measurements such as needle grabbing, first tie, second tie and final knot did not show any significant difference between the two instruments. Upward suture also did not show a significant difference. The total completion time was 127 vs. 112 seconds for for ArtiSential ${ }^{\circledR}$ and the robot, respectively $(p=0.675)$. Time taken in each interval did not show any significant difference.

Conclusion: Both instruments performed the suturing tasks with no difference in duration. ArtiSential ${ }^{\mathbb{B}}$ can be mixed up with usual instruments. Surgeons can choose any device, but when articulation is needed, ArtiSential ${ }^{\circledR}$ could be an alternative choice to the robotic system.
Received May 27, 2019

Revised 1st June 30, 2019 2nd July 24, 2019

Accepted August 6, 2019

Corresponding author

Sang-Hoon Ahn

Department of Surgery, Seoul National University Bundang Hospital, 82

Gumi-ro 173 Beon-gil, Bundang-gu, Seongnam 13620, Korea

Tel: $+82-31-787-7099$

Fax: +82-31-787-4078

E-mail: viscaria@snubh.org ORCID:

https://orcid.org/0000-0001-8827-3625

This study presented at KSELS 2018, SAGES 2018, EAES 2018.

Keywords: Laparoscopy, Articulation, Instrument, Robotics, Suture

This is an Open Access article distributed under the terms of the Creative Commons Attribution Non-Commercial License (http:// Copyright (c) 2019 The Journal of Minimally creativecommons.org/licenses/by-nc/4.0/) which permits unrestricted non-commercial use, distribution, and reproduction in any Invasive Surgery. All rights reserved. medium, provided the original work is properly cited.

\section{INTRODUCTION}

Laparoscopic surgery has become essential in surgical training in most institutions. The development of laparoscopic instruments and the safety of laparoscopic technique has led to an era of minimally invasive surgery. ${ }^{1}$ A conventional laparo- scopic instrument usually has very limited degree of freedom (DOF), it can only open, close and rotate. Now that surgeons are comfortable with laparoscopic technique, ergonomics has become an important issue in terms of surgeons' fatigability. The da Vinci ${ }^{\circledR}$ Robotic System has been the most ergonomic instrument with the widest range of motion. ${ }^{2}$ However, low 
cost-effectiveness and low clinical usage have been reported in numerous studies. ${ }^{3,4}$

There are several devices with articulation such as Cambridge Endo and Novare RealHand. However, there are no studies evaluating these devices. Clinical application was limited and both companies have stopped developing the devices. The most recent articulating instrument is the FlexDex, which is more intuitive than others. FlexDex has made a great effort to provide a purely mechanical method of articulation. ${ }^{5}$

This is the first paper to introduce this new multi-DOF articulating instrument. In order to evaluate its function, we designed a simple, pragmatic, but difficult suturing task. In laparoscopic setting, normal and comfortable suturing consists of a parallel placement of the needle holder and the suture site. Sometimes the tissue can be pulled or pushed to make this angle. However, to achieve minimal tissue manipulation, difficult sutures are necessary. In this study, we compared the time consumption in performing difficult angled sutures, between the new multi-DOF articulating instrument and the robotic system.

\section{MATERIALS AND METHODS}

\section{Participants}

Five surgeons were asked to perform suture tasks. One participant was a colorectal surgeon, another a hepatobiliary surgeon and the other three were upper gastrointestinal surgeons. No one had experience with any other articulating instruments including the robotic system before this study. All five surgeons were experts with more than 100 cases of laparoscopic surgical procedures such as laparoscopic appendectomy, colectomy, gastrectomy, and cholecystectomy. They had enough time to handle both instruments and had one chance of doing the suture task as a practice, before the actual timing of the task.

\section{Laparoscopic instruments}

The Endoeye ${ }^{\circledR}$ Flex 3D system (Olympus, PA, USA) was used for the new multi-DOF articulating instrument in order to balance the laparoscopic view since the robotic system had built in 3D imaging system. The camera was held in a static scope holder (Laparostat ${ }^{\circledR}$, CIVCO, IA, USA). The da Vinci $S^{\oplus}$ Robotic Surgical System (Intuitive Surgical Inc., Sunnyvale, CA, USA) served as the control group for comparison, and a 30-degree stereoscope and two standard needle drivers were used.

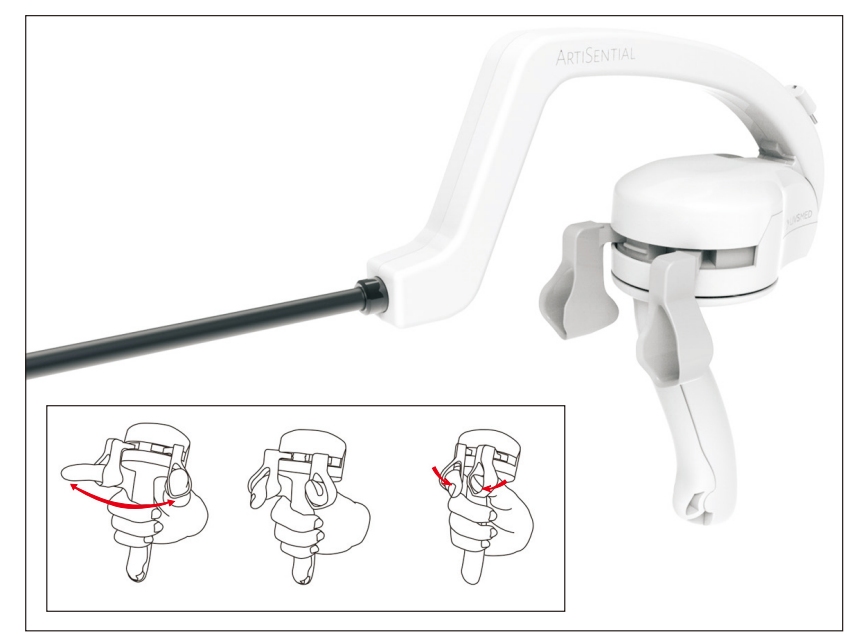

Fig. 1. ArtiSentia ${ }^{\circledR}$ instrument handle. The thumb and the index finger, mainly used for grabbing, goes into the two holes on the handle. The movement of this handle and the end tool shows identical motion.

\section{ArtiSential $^{\circledR}$}

The new Multi-DOF articulating laparoscopic instrument is called ArtiSential ${ }^{\circledast}$ (LIVSMED, Seongnam, Republic of Korea). It has a multi-joint structure which works with a Pulley mechanism, whereas the end tool of the conventional laparoscopic instrument has no joint. Because of this structure, the end tool of ArtiSential ${ }^{\oplus}$ can move $90^{\circ}$ up, down, left, and right. The thumb and index finger go into the two holes of the handle (Fig. 1). The free manipulation provides intuitive movement of the end tool that perfectly matches the movement of the user's fingers and wrists (Fig. 2). The rest of the fingers grab the main handle for support and on the main handle there is switch which you can push forward to enable the "Hold" mode. The "Hold" mode can fix the end effector at any angle and allow only the grasping motion of ArtiSential ${ }^{\circledR}$ which turns it into a conventional instrument. For this study, we used the ArtiSential ${ }^{\circledR}$ Needle holder on the right hand and the ArtiSential ${ }^{\circledR}$ Grasper on the left hand (Fig. 3).

\section{Task}

The suturing task consisted of two challenging sutures. Upon deciding the angle of a simple but difficult suture, vertical suture was the most challenging as they were done in a suture exercise kit.

First was a downward suture and then an upward suture, perpendicular to the suture line (Fig. 4). The duration of time was measured as shown in Table 1 and 2, from the moment the left grasper held the needle for preparation until it passed through the suture line with the needle holder (Needling), and 

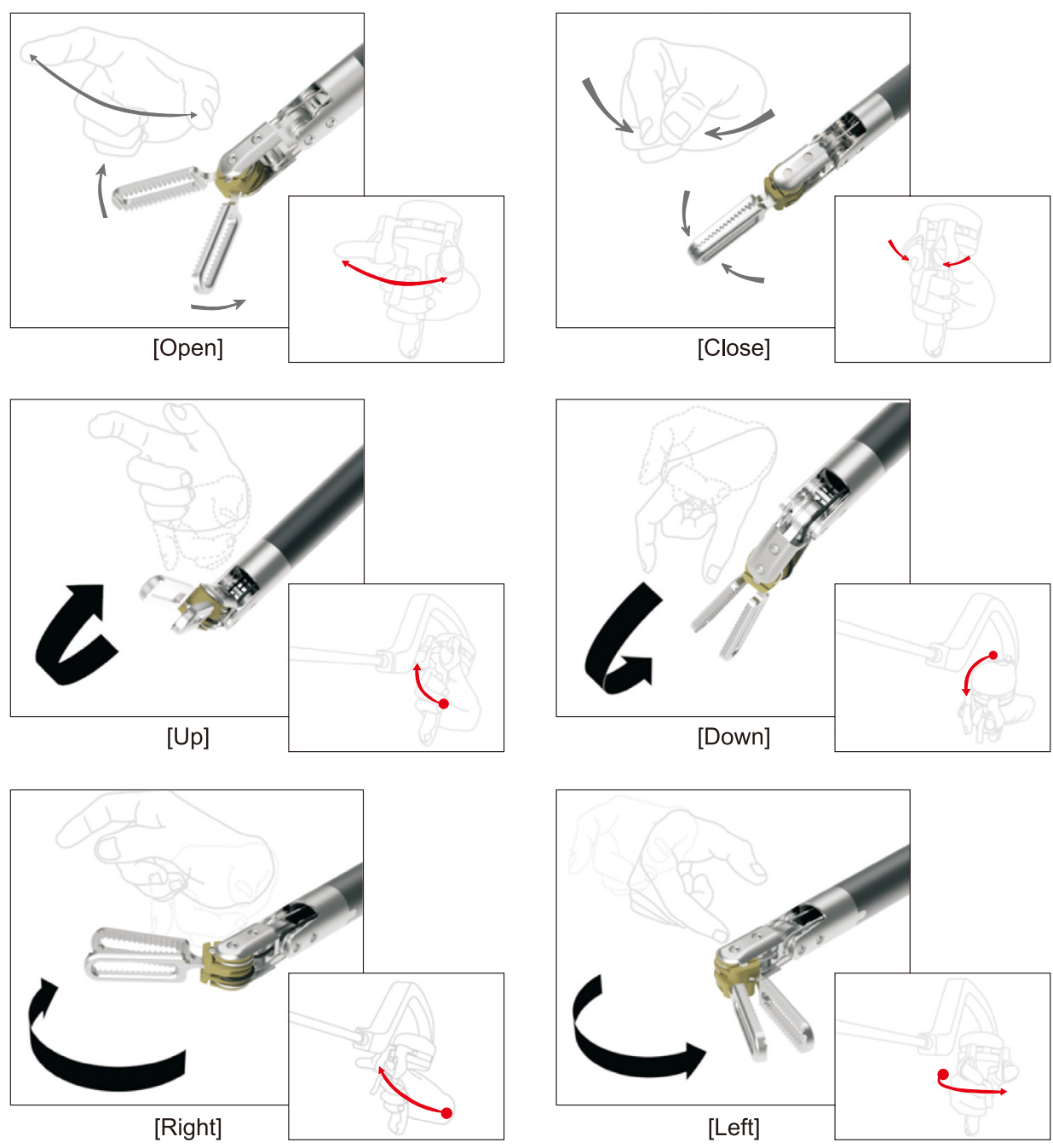

Fig. 2. ArtiSential ${ }^{\circledR}$ instrument handend tool coordination. The movement of the thumb, index finger and the wrist perfectly match the movement of the end tool.
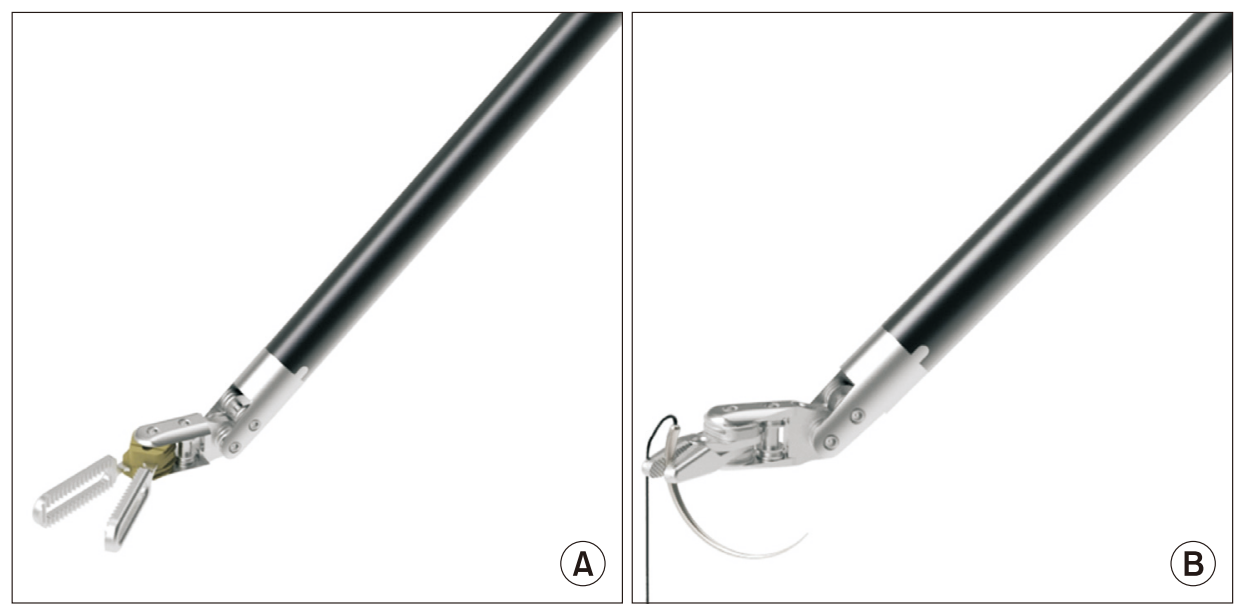

Fig. 3. (A) ArtiSential ${ }^{\circledR}$ Bipolar Fenestrated Grasper, (B) ArtiSential ${ }^{\circledR}$ Needle Holder.

then a surgical tie (First), a square tie (Second), and finally a reverse tie (Final). Cutting of finished tie at the end was done manually. This downward and upward direction of suturing can be observed in many laparoscopic situations.
The suturing task was performed with a $20 \mathrm{~cm} 3 \sim 0$ Vicryl suture on a silicone suture pad (Medical grade silicone surgical suturing pad, GoooDol, DongGuan City, China). The suture was done inside a Robotic Exercise Kit (The Chamberlain 
Group, MA, USA) (Fig. 5).

In order to ensure accurate and high-quality results, no verbal or physical guidance was provided to the participants when they had technical difficulty.

This study protocol was approved by the Institutional $\mathrm{Re}^{-}$ view Board (IRB No. N-1709-423-602).

\section{Statistical analysis}

The data were analyzed using the statistical software $\mathrm{R}$ (Version 3.3.2, R Foundation for Statistical Computing, Vienna, Austria). The time duration at each step was compared between the two methods by Fisher's exact test. $p$ value $<0.05$ was considered to be statistically significant.

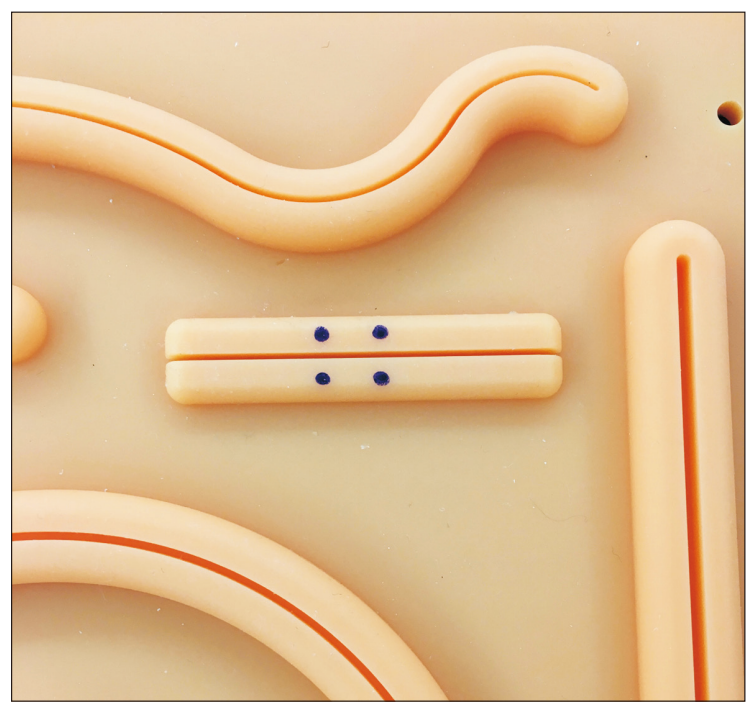

Fig. 4. Suture task pad. The matching vertical dots are targets for up and down vertical sutures.

\section{RESULTS}

The two instruments were compared separately.

In downward suture, the median time to complete the suture was 127 vs. 136 seconds for ArtiSential ${ }^{\circledR}$ and da Vinci ${ }^{\circledR}$, respectively ( $p=0.754$, Table 1). Needling time, first knot, second knot and final knot did not show any significant difference between the two instruments (Table 1).

Upward suture also did not show statistical significance. The total completion time was 127 vs. 112 seconds for ArtiSential ${ }^{\circledR}$

Table 1. Time taken to complete the Downward Suture

\begin{tabular}{lccc}
\hline & $\begin{array}{c}\text { ArtiSentia }^{\circledR} \\
(\mathbf{N}=5)\end{array}$ & $\begin{array}{c}\text { da Vinci }^{\circledR} \\
(\mathbf{N}=5)\end{array}$ & $p$ value \\
\hline Total completion time & $127(99,192)$ & $136(129,148)$ & 0.754 \\
Needling time & $78(64,98)$ & $72(65,80)$ & 0.675 \\
First knot & $14(12,20)$ & $17(13,20)$ & 0.834 \\
Second knot & $13(12,17)$ & $24(16,30)$ & 0.347 \\
Final knot & $11(9,22)$ & $24(14,32)$ & 0.251 \\
\hline
\end{tabular}

All values are expressed as the median and ranges, in seconds.

Table 2. Time taken to complete the Upward Suture

\begin{tabular}{lccc}
\hline & $\begin{array}{c}\text { ArtiSential } \\
(\mathbf{N}=5)\end{array}$ & $\begin{array}{c}\text { da Vinci }^{\circledR} \\
(\mathbf{N}=5)\end{array}$ & $p$ value \\
\hline Total completion time & $127(107,168)$ & $112(101,142)$ & 0.675 \\
Needling time & $66(57,113)$ & $66(57,70)$ & 0.753 \\
First knot & $12(10,15)$ & $13(12,20)$ & 0.595 \\
Second knot & $25(25,26)$ & $23(19,23)$ & 0.115 \\
Final knot & $15(14,17)$ & $13(9,37)$ & 0.754 \\
\hline
\end{tabular}

All values are expressed as the median and ranges, in seconds.
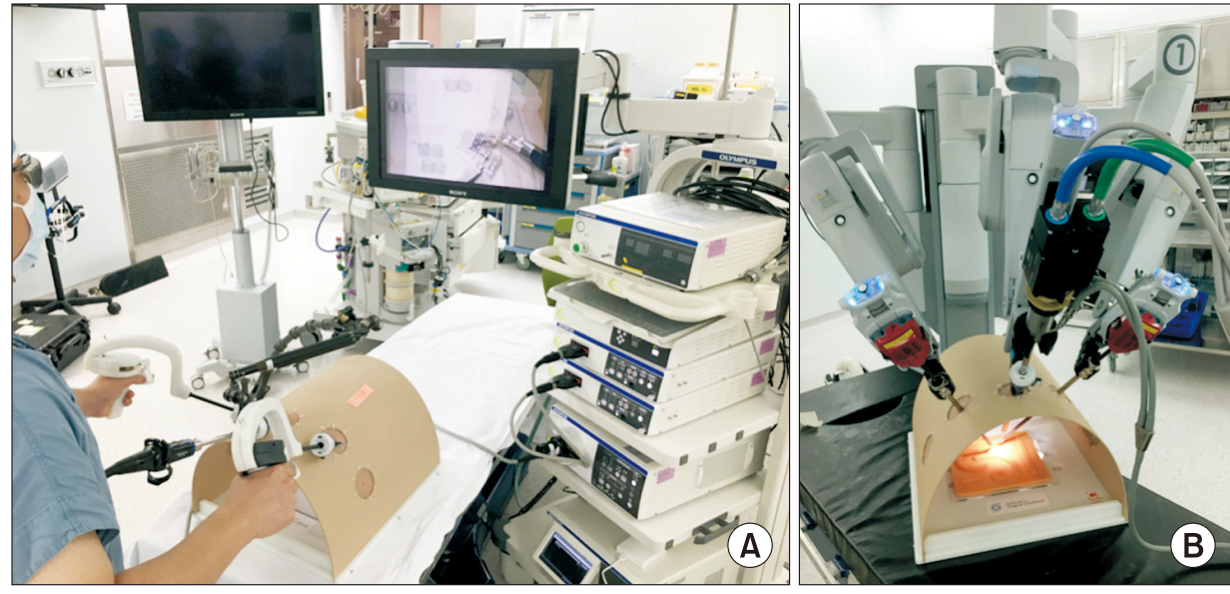

Fig. 5. (A) Setting for suture task with ArtiSentia ${ }^{\circledR}$ instruments. (B) Robotic setting for suture task with da Vinci ${ }^{8}$ surgical system. 
and da Vinc ${ }^{\circledR}$, respectively ( $p=0.675$, Table 2$)$. Time taken in each interval did not show any significant difference (Table 2).

The total completion time of downward suture and upward suture within each group, did not show any significance. ArtiSential $^{\circledR}$ showed a median total completion time of 127 seconds in downward suture and 127 seconds in upward suture $(p=0.474)$. da Vinci $^{\circledR}$ showed a median total completion time of 136 seconds in downward suture and 112 seconds in upward suture $(p=0.133)$.

\section{DISCUSSION}

We are living in an era of minimally invasive surgery (MIS). Since the introduction of laparoscopy, there has been tremendous development in the surgical area. Behind this is the advancement of laparoscopic devices including instruments, camera technology and energy-based devices. Many studies have proven the superiority of laparoscopy to open surgery, 6,7 and many hospitals worldwide have implemented laparoscopy as the primary choice of surgical approach. However, compared to open surgery, laparoscopy lacks several features such as freedom of movement, and tactile sense. There are various ongoing attempts to integrate tactile sense into the laparoscopic instruments such as pneumatic, acoustic reflection, and Stochastic resonance, but no actual product has come out yet. $^{8-10}$ Some articulating laparoscopic devices with increased freedom of movement are already in the market. However, most products have been unsuccessful. The most effective tool so far is the da Vinci ${ }^{\circledR}$ robotic system. ${ }^{2}$ A critical problem the da Vinci ${ }^{\circledR}$ system has since its introduction is the price, thus the low cost-effectiveness. ${ }^{3,4}$ Other problems besides cost, are small quantity of units per institution and the need for specific room and staff to prepare the machine. There are many institutions worldwide that have the da Vinci ${ }^{\circledR}$ system but most of them have one or two units proving the high cost and low usage. Also, there has to be an operating theater designated to robotic surgery and the expert staff to prepare the console, robotic arms and mounting/dismounting instruments. Not all institutions have all types of robotic arms, so some procedures require laparoscopic instruments (such as staplers, suction devices, etc). Based on these problems, an articulating device just like the da Vinci $^{\circledR}$ that can be used in regular laparoscopy surgery had to be developed. ArtiSential ${ }^{\circledR}$ is the first multiDOF articulating laparoscopic device with the widest angle of motion, a perfect 360 degrees (Fig. 2). No other articulating device can do this except for the da Vinci ${ }^{\circledR}$. Therefore, comparison of the function between ArtiSential ${ }^{\circledR}$ and da Vinci $^{\circledR}$ was necessary.

During laparoscopic surgery, there are situations when the instrument is at a difficult angle to perform a certain task.
Normally, surgeons do not insert another trocar just because the angle is not right. In this study we calculated the angle of the conventional laparoscopic instrument and the suture line of the exercise pad so that it can represent a difficult suturing angle. A vertical suture seemed suitable for the task. The initial needling time took the most time because all five surgeons were not familiar with articulation, so the task of holding the needle was a difficult step. After initiation of needling, first, second and final knot was straight forward. Most of them took more time in the second knot and this might be because it was a reverse tie. With surgeons accustomed to straight instruments, the addition of articulation when making a knot can be overwhelming especially when you have to hold the sutures differently for a reverse tie. The duration of each step did not make any significant difference, showing similar efficacy.

The results of this study should not be construed as a simple comparison of two devices. There are many types of laparoscopic instruments in the market and surgeons choose which device to use according to their preferences. In selecting instruments, there lies several problems such as price, availability, and assistants in the operating room. These are some of the factors that surgeons think about when adopting new devices. Although the results showed no statistical difference in suturing time between ArtiSential ${ }^{\circledR}$ and da Vinci $^{\circledR}$, some surgeons might choose ArtiSential ${ }^{\circledR}$ for its handiness, price and no need for assistance.

Haptic feedback is an important issue in laparoscopic surgery. There are numerous experimental studies concerning decreased feedback in laparoscopic setting. The use of laparoscopic instruments decreased tissue recognition by $20 \%$ and the grip strength was almost twice the necessary amount to manipulate the tissue. ${ }^{11,12}$ Unlike da Vinci $^{\circledR}$, ArtiSential ${ }^{\circledR}$ is directly connected to the wired articulating joint mechanism. With this, the resistance from the tissue or object between the jaws of the instrument can be sensed. While doing the suturing tasks with da Vinci $^{\circledR}$, there was no tension felt by pulling the suture, because of the absence of haptic feedback. ${ }^{13}$ This was not an issue with ArtiSential ${ }^{\circledR}$.

There are several limitations to this study. First of all, only five experienced surgeons were recruited, and the tasks were done only once. However, since we were not doing a complicated task and not trying to see a learning curve or improvement of using the instruments, not many subjects were required for the comparison. If subjects had repeated the tasks, they would have eventually improved, which is not the point of our study. Also, we did not include novice and intermediate experienced surgeons because the familiarity of conventional laparoscopic instruments was essential in order to compare with da Vinci ${ }^{\circledR}$ and derive our conclusive points. Second, the fatigability of using the instruments could have 
been measured. Upon using both instruments for the first time, the surgeons experienced fatigue to their muscles and joints. Fatigability was not the focus of this study, but it would have improved the quality of this study. Third, the quality of each suture steps was not accounted for. Some of the ties were slightly loosened but had continued with the next step. If each task was supervised, the time duration might have been different. Last, only difficult suture tasks were included in the study. Easier tasks such as peg transfer and pattern cutting were not included. This was because we designed this study to compare the two instruments in difficult settings. In order to gather more concrete and convincing data, a preclinical study is being prepared.

We introduced this new type of articulating laparoscopic device which actualized the robotic arms of da Vinci ${ }^{\circledR}$ but useable in normal laparoscopic surgery. In this study, experienced laparoscopic surgeons who were new to articulating devices, could achieve irritating and difficult suturing tasks with ArtiSential $^{\circledR}$ just as good as the da Vinci ${ }^{\circledR}$. ArtiSential ${ }^{\circledR}$ can be more flexibly used by surgeons mixing up with usual instruments. Sometimes in the middle of a difficult surgery where articulation is needed but a sudden change to the da Vinci ${ }^{\circledR}$ is impossible, ArtiSential ${ }^{\circledast}$ could be an alternative choice.

\section{ORCID}

Sa-Hong Min, https://orcid.org/0000-0002-6150-7935

Yo-Seok Cho, https://orcid.org/0000-0002-2436-287X

Kibum Park, https://orcid.org/0000-0001-5404-5667

Yoontaek Lee, https://orcid.org/0000-0003-2643-2007

Young Suk Park, https://orcid.org/0000-0002-6352-9759

Sang-Hoon Ahn, https://orcid.org/0000-0001-8827-3625

Do Joong Park, https://orcid.org/0000-0001-9644-6127

Hyung-Ho Kim, https://orcid.org/0000-0002-6267-1550

\section{AUTHORS' CONTRIBUTIONS}

Conceptualization: SHA, DJP, HHK. Formal analysis: SHM, YSC. Methodology: KBP, YTL. Writing-original draft: SHM. Writing-review and editing: SHM, KBP, YTL, YSP, SHA, DJP, HHK.

\section{CONFLICT OF INTEREST}

Yes (ArtiSential instruments were provided by Livsmed ${ }^{\mathrm{TM}}$, Korea).

\section{FUNDING}

None.

\section{ACKNOWLEDGMENTS}

We thank Intuitive Surgical Inc. for providing exercise arms for da Vinci ${ }^{\circledR}$ Si surgical system.

\section{REFERENCES}

1) Kim HH, Hyung WJ, Cho GS, et al. Morbidity and mortality of laparoscopic gastrectomy versus open gastrectomy for gastric cancer: an interim report--a phase III multicenter, prospective, randomized Trial (KLASS Trial). Ann Surg 2010;251:417420.

2) Fan G, Zhou Z, Zhang H, et al. Global scientific production of robotic surgery in medicine: A 20-year survey of research activities. Int J Surg 2016;30:126-131.

3) Close $A$, Robertson $C$, Rushton $S$, et al. Comparative cost-effectiveness of robot-assisted and standard laparoscopic prostatectomy as alternatives to open radical prostatectomy for treatment of men with localised prostate cancer: a health technology assessment from the perspective of the UK National Health Service. Eur Urol 2013;64:361-369.

4) Kim HI, Han SU, Yang HK, et al. Multicenter Prospective Comparative Study of Robotic Versus Laparoscopic Gastrectomy for Gastric Adenocarcinoma. Ann Surg 2016;263:103-109.

5) Awtar S, Trutna TT, Nielsen JM, Abani R, Geiger J. FlexDex ${ }^{\mathrm{TM}}$ : a minimally invasive surgical tool with enhanced dexterity and intuitive control. J Med Device 2010;4:035003.

6) Kim HH, Han SU, Kim MC, et al. Long-term results of laparoscopic gastrectomy for gastric cancer: a large-scale case-control and case-matched Korean multicenter study. J Clin Oncol 2014; 32:627-633.

7) Park DJ, Han SU, Hyung WJ, et al. Long-term outcomes after laparoscopy-assisted gastrectomy for advanced gastric cancer: a large-scale multicenter retrospective study. Surg Endosc 2012;26: 1548-1553.

8) Ly HH, Tanaka Y, Fukuda T, Sano A. Grasper having tactile sensing function using acoustic reflection for laparoscopic surgery. Int J Comput Assist Radiol Surg 2017;12:1333-1343.

9) Lee C, Park WJ, Kim M, et al. Pneumatic-type surgical robot endeffector for laparoscopic surgical-operation-by-wire. Biomed Eng Online 2014;13:130.

10) Sawada H, Egi H, Hattori M, et al. Stochastic resonance enhanced tactile feedback in laparoscopic surgery. Surg Endosc 2015;29: 38113818.

11) Ottermo MV, Ovstedal M, Lango T, et al. The role of tactile feedback in laparoscopic surgery. Surg Laparosc Endosc Percutan Tech 2006;16:390-400.

12) Heijnsdijk EA, Pasdeloup A, van der Pijl AJ, Dankelman J, Gouma DJ. The influence of force feedback and visual feedback in grasping tissue laparoscopically. Surg Endosc 2004;18:980- 
985.

13) Alleblas CCJ, Vleugels MPH, Coppus S, Nieboer TE. The effects of laparoscopic graspers with enhanced haptic feedback on applied forces: a randomized comparison with conventional graspers. Surg Endosc 2017;31:5411-5417. 